\title{
Permeability characteristics of the human nail plate
}

\author{
K. A. WALTERS and G. L. FLYNN*, Fisons plc, Pharmaceutical Division, Bakewell Road, \\ Loughborough LE11 OQY, U.K. and *University of Michigan, College of Pharmacy, Ann \\ Arbor, Michigan 48109 , U.S.A.
}

Presented in part at the Society of Cosmetic Scientists Meeting, Bristol, November 1981

Key words: nail plate, cosmetic toxicity, diffusion barrier.

\begin{abstract}
Synopsis
The permeation of chemicals across the nail plate and their consequent effects are discussed in relation to cosmetic toxicity and possible clinical efficacy. The reviewcd data are then assessed and placed in context with recent observations on the direct assessment of permeability of the human nail plate. Although marked differences between the diffusional barrier characteristics of nail and stratum corneum are shown, a reasonably unified picture of nail plate permeability is drawn from the collective observations. The cosmetic and clinical implications of chemical penetration of the nail plate are briefly outlined and places where knowledge needs to be strengthened are identified.
\end{abstract}

La perméabilité de l'ongle humain

Résumé

La pénétration des substances chimiques au travers de l'ongle et ses conséquences sont examinées en fonction de la nature anatomique, histologique et chimique de l'ongle humain.

La perméabilité de l'ongle peut être mise en évidence par la toxicité de certaines substances chimiques ou plus directement par le contrôle topique de maladies spécifiques de l'ongle telle que l'onychromycose.

On fait un parallèle entre les données bibliographiques et de récentes observations sur l'évaluation directe de la perméabilité de l'ongle humain. Le point remarquable des données bibliographiques est la différence entre les caractéristiques de barrière de diffusion de l'ongle humain et le stra tum cornéum. Alors que le stratum cornéum agit pour l'essentiel comme une barrière hydrophobe, l'ongle apparaît être un continu hydrophile à de nombreux agents de pénétration. Les observations physicochimiques et chimiques mènent à une même conclusion à savoir que l'ongle est perméable à toute un série de substances allant des sels et des nonelectroly tres polaires ou apolaires aux grosses molécules complexes que sont certains médicaments. Il semble toutefois probable que nombre de substances qui viennent en contact avec l'ongle, soit de façon délibérée pour des raisons cosmétiques ou médicales, soit de façon accidentelle, diffusent au travers de l'ongle et la menace d'une certaine toxicité existe toujours pour les individus sensibles. Bien que de nombreux domaines requèrent un connaissance plus approfondie, il apparaît probable que les cosmétologues seront bientôt en mesure de sélectionner avec plus de prudence les matières premières pour les préparations pour les ongles et de minimiser ainsi les conséquences néfastes de l'absorption pérungueale.

Correspondence: Kenneth A. Walters, Fisons plc, Pharmaceutical Division, Bakewell Road, Loughborough, LE11 OQY, U.K.

0142-5463/83/1200-0231\$02.00@ 1983 International Journal of Cosmetic Science 


\section{INTRODUCTION}

The application of chemicals to enhance the appearance of the human nail has been practised for many centuries. Hypersensitivity and onychodystrophies due to components of the nail cosmetic, however, do not appear to have been recognized until 1937 (1). During the following two decades additional reports on the onychodystrophic effects of nail cosmetics have been published. Dystrophies observed ranged from slight discoloration (2) to onycholysis (separation of the nail plate from the nail bed) (3). Recent reports of such phenomena are sparse probably because modern formulations have been made hypoallergenic by removing known offending chemicals.

Chemical toxicity to the nails is not confined to cosmetic formulations. Reports concerning the onychodystrophic effects of detergents (4), pesticides (5) and mercurial ointments (6) used in the home and workplace have been published. Nor is it necessary for the dystrophic agent to contact the nail plate directly for toxic reactions to occur. Nail dystrophies such as onycholysis (7) and photo-onycholysis (8) have been reported following systemic administration of antibiotics.

This article reviews the literature concerned with nail toxicities of chemicals. The reviewed data are then assessed and placed in context with recent observations on the direct assessment of permeability of the human nail plate. A reasonably unified picture of nail plate permeability is drawn from the collective observations and places where knowledge needs to be strengthened are identified.

\section{ANATOMICAL, HISTOLOGICAL AND CHEMICAL NATURE OF THE HUMAN NAIL}

The human nail is depicted in Fig. 1. The sketches are representative of nails of both hand and foot and they define the anatomical terms sprinkled throughout the remainder of the text. The nail plate is the most prominent anatomical feature and in man it exists as a relatively thin (typically $0.5-1.0 \mathrm{~mm}$ ) plate $(9)$ which exhibits a gentle convex curvature in both $\mathbf{x}$ and $y$ directions when viewed from above.

The nail plate is comprised of layers of flattened, keratinized cells fused into a dense but somewhat elastic mass (10). These cells have their origins in the nail matrix, a living, highly proliferative epidermal tissue (11). The nail normally grows distally at the rate of about $0.1 \mathrm{~mm}$ per day and thus requires from 4 to 5 months to completely regenerate after avulsion $(12,13)$. It has been demonstrated that growth is slowed with increasing age (12), by cold climatic conditions (12), in disease states with reduced blood flow to the body's periphery (12) and in malnutrition (14), all of which indicate that proliferative events in the nail matrix are very sensitive to the local availability of nutrients.

The nail plate is surrounded on three sides and is set into a grooved epidermal invagination known as the nailfold. The folds are comprised of a typical cornified epithelium and they produce the soft keratinized nailfold flap or extension known as the eponychium or cuticle. The nail plate overlays the nail bed, a soft and normally non-cornified tissue. Cells in the nail bed at the plate-nail bed interface are carried distally by the nail plate in the course of its growth. In the absence of outward pressure of the growing nail plate these cells are stationary (15).

The nail plate is formed in the nail matrix from cells originating in both the dorsal and ventral aspects of the nail matrix. The matrix appears as a semilunar area at the proximal ventral surface of the nail groove. It may be totally recessed under the nailfold or may extend outwards from the fold as a white area called the lunula. Cell division occurs in the outermost 
(a) Top view

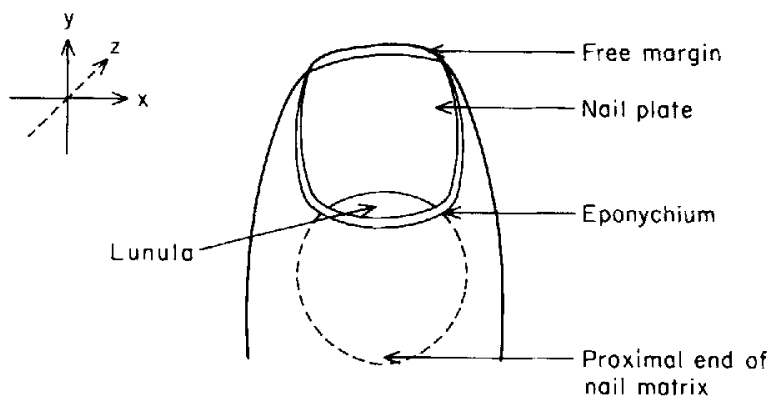

(b) Cross-section

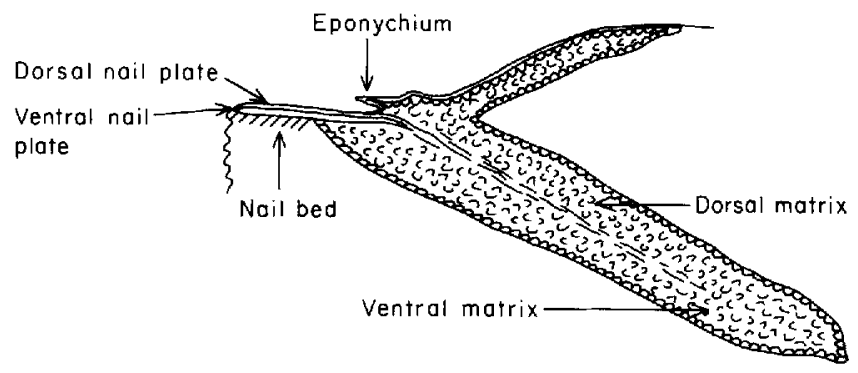

Figure 1. Major features of the human nail.

envelope of cells of the matrix on both sides of the forming nail plate. The cells push simultaneously distally and inwards towards the centre of the matrix.

Keratinization of cells takes place roughly along the matrix axis about $25 \%$ of the way out from the apex. In the keratinization process the cells undergo shape and other changes similar to those experienced by epidermal cells forming the stratum corneum and the hair $(10,16,17)$. These enter the forming nail plate in tightly knit layers and about twenty-five layers of cells comprise the finished nail. The compactness of the plate is governed by 'dovetailing' of the cells and tight binding of the cells with numerous intercellular links $(10,18)$. Some evidence indicates there are also perpendicularly orientated fibres of keratin in the outermost segments which contribute to the fusing together of the layers $(19,20)$. Most of the keratin fibres are orientated in the x-axis (Fig. 1) in the plane of the nail or perpendicular to the axis of growth. The structure is so tightly knit that there is no cell cxfoliation as occurs in stratum corneum unless pathogenic stimuli are present. Although the normal nail visually appears uniform from surface to surface there are at least two discernible macroscopic strata $(20,21)$, with possibly a third $(16,22)$. These are the dorsal nail plate and the intermediate nail plate with the third, sometimes observed, under-layer or ventral plate contributed by the cells of the lunula. The dorsal nail plate appears to be a harder laminate and, as mentioned, it has a perpendicularly orientated fibrous fraction which may be responsible for its unique properties. The intermediate nail plate is a softer and more flexible tissue whose extra thickness is obviously the result of more cell layers being deposited over a broader area than occurs dorsally. The ventral plate is very thin and contains only one or two layers of cells (23). 
Table I. Amino acid composition of various keratinized tissue (27)

\begin{tabular}{lccc}
\hline Amino acid & Hair & Nail & Stratum corneum \\
\hline Lysine & $2.5^{\mathrm{a}}$ & $3.1^{\mathrm{a}}$ & $4.2^{\mathrm{a}}$ \\
Histidine & 0.9 & 1.0 & 1.5 \\
Arginine & 6.5 & 6.4 & 3.8 \\
Aspartic acid & 5.4 & 7.0 & 7.9 \\
Threonine & 7.6 & 6.1 & 3.0 \\
Serine & 12.2 & 11.3 & 13.6 \\
Glutamic acid & 12.2 & 13.6 & 12.6 \\
Proline & 8.4 & 5.9 & 3.0 \\
Glycine & 5.8 & 7.9 & 24.5 \\
Alanine & 4.3 & 5.5 & 4.4 \\
Valine & 5.5 & 4.2 & 3.0 \\
Methionine & 0.5 & 0.7 & 1.1 \\
Isoleucine & 2.3 & 2.7 & 2.7 \\
Leucine & 6.1 & 8.3 & 6.9 \\
Tyrosine & 2.2 & 3.2 & 3.4 \\
Phenylalanine & 1.7 & 2.5 & 3.2 \\
Halfcystine & 15.9 & 10.6 & 1.2 \\
Sulphur & $4.5 \%^{\mathrm{b}}$ & $3.2 \%^{\mathrm{b}}$ & $1.4 \%^{\mathrm{b}}$ \\
\hline
\end{tabular}

${ }^{\text {a }}$ Expressed as residues per 100 residues.

${ }^{b}$ Expressed as per cent of dry weight.

The nail plate is hardly remarkable chemically given that it is a cornified epithelial structure. Nitrogen is its major component (24), attesting to its proteinaceous nature, and it contains trace amounts of the metallic elements $\mathrm{Ca}, \mathrm{Mg}, \mathrm{Na}, \mathrm{Fe}, \mathrm{Cu}$ and $\mathrm{Zn}(25,26)$. A significant amount of sulphur is present as the sulphide and disulphide functional groups of the sulphurcontaining amino acids of keratin $(27,28,29)$. The complete list of amino acids comprising the nail plate are compared with those from hair and stratum corneum in Table I (27). It can be seen that the nail plate is compositionally more like hair than stratum corneum. This is also true of its thermo-analytical (30), mechanical (27) and moisture-retaining behaviour. The nail plate contains cholesterol as its principle lipid and as a plasticizer (24). The extraction of cholesterol results in dry and brittle nails. The total fat content of mature nail material lies between 0.1 and $1.0 \%$ in marked contrast to the approximately $10 \%$ lipid content of stratum corneum (31). Water is the principle plasticizer of the nail and is typically present at between 7 to $12 \%$. The moisture content may be lower under very dry conditions and higher under very humid conditions $(20,27)$. The upper limit of the nail plate's capacity for water appears to be about $25 \%$ (27) which marks another striking contrast to stratum corneum which, under average conditions, contains about 15 to $25 \%$ water and which may imbibe several times its dry weight in water at $100 \%$ relative humidity (32).

For a fuller description of the anatomy and biochemistry of the human nail, the reader is referred to Spearman's review (23).

\section{MEMBRANE PROPERTIES OF THE HUMAN NAIL PLATE}

The nail plate has been described as a laminated structure microscopically layered as sheets of cells and macroscopically consisting of two principle strata, the dorsal and intermediate plates. The entire fabric is hard keratin and the external-most dorsal layer is especially dense. The thickness of the entire structure approaches and may exceed $0.1 \mathrm{~cm}$. Given the high 
refractivity to permeation exhibited by the skin's stratum corneum, which is only about $0.001 \mathrm{~cm}$ in thickness over most of the body's surface, it would not be totally unreasonable to write off the nail as an all but impermeable barrier. However, on examination of the literature, it appears that this judgement is too quick and substantially inaccurate. Most of the evidence that the nail is somewhat permcable is indirect in that it is either associated with toxicities of various chemicals or, on the more positive side, is associated with the successful topical control of nail diseases such as onychomycoses and psoriasis of the nails. Direct evidence is relatively sparse but on a few occasions investigators have measured actual mass transport rates across the nail plate. These three groups of evidence will be considered separately.

\section{Toxicity as a measure of permeability}

Perhaps the first indication that nail cosmetics may induce hypersensitivity was made in 1937 by Sulzberger (1). Irritation and rashes on the face, neck and periungual areas were believed to be due to the red dye present in the nail lacquers of concern. Since this observation there have been several additional mentions of toxicities from nail cosmetics including lacquers, hardeners and under-coats. Either allergic reactions or frank chemical irritations of the nail bed have resulted in tissue responses ultimately manifested as partial or total loosening of the nail plate. Sulzberger et al. (33) noted a rash of such incidents in 1947 as a response to a nail polish under-coat, Everon (Revlon Products Corp.). The formulation was reported to be a solution of phenol-formaldehyde resins and synthetic rubbers in methyl cthyl ketone. A similar report was filed by Rein and Rogin (3) and, based on patch tests, they concluded that the resin was the causative factor. It was also suggested that the injurious chemicals 'may dialyse through the nail plate', a supposition which had been experimentally shown previously (34) where under-coat was applied to one surface of avulsed nails and phenol was detected on the other side.

Nail changes were again observed after the use of an under-coat reputedly containing twenty-two ingredients but no synthetic rubber or formaldehyde resins (35). In this case the changes noted were not perceived as due to allergic sensitivity but to the occlusive nature of the under-coat. Several years later, however, a series of adverse reactions to a nail hardener formula, Strong and Long (Helena Rubinstein $\mathrm{Co}$.), which contained 7\% formaldehyde, were reported $(36,37,38,39)$. In March 1966 Strong and Long was recalled by the FDA following approximately ninety reports of nail damage (37).

Another type of nail cosmetic which has been shown to cause allergic scnsitization is 'stick-on' nails (40). The self-curing acrylic resins associated with these products are created by inducing polymerization of a mixture of methyl methacrylate monomer and polymethyl methacrylate powder, with an organic peroxide and an accelerator. Methyl methacrylate monomer proved to be the allergen in the formula. Ready-fashioned synthetic nails, composed of nitrocellulose and applied with an adhesive substance containing cellulose acetate dissolved in butyl acetate and a plasticizer were also shown to cause damage. This was ascribed mainly to their occlusive effects (41). A brief review on the subject of dystrophies due to nail cosmetics has been given by Bentley-Phillips (42).

Typical ingredients of modern nail enamels are given in Table II (43). It is interesting to note that formaldehyde resins are still in use, although they are not present in hypoallergenic nail enamels. It is also at first surprising that some of the harsh solvents employed are not associated with untoward reactions of the nail bed.

Of equal significance are reports of onychodystrophies and onycholysis due to the topical use of drugs such as 5-fluorouracil. This is applied in solution and cream vehicles to treat 
Table II. Modern nail enamel ingredients (43)

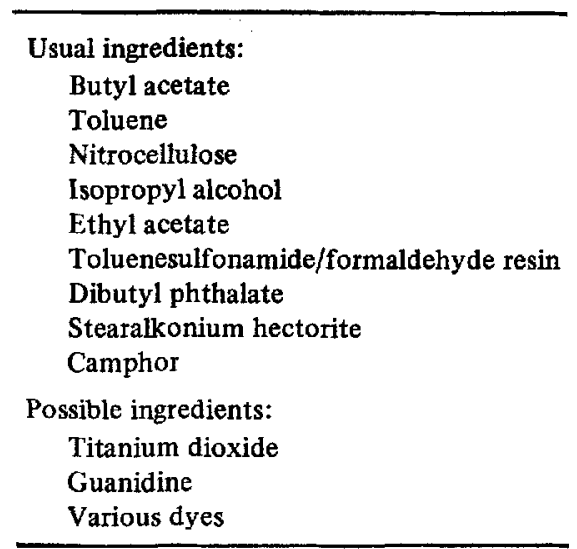

paronychial warts $(44,45,46)$. Shelley (46) indicates that application of $5 \%$ fluorouracil with occlusion can lead to a sloughing of the nail plate (dramatic onycholysis), a response which can also be induced by injecting 5-fluorouracil under the nail bed. The suggestion is strong that clinically significant amounts of 5-fluorouracil are perungually absorbed. It should be noted that systemic administration of fluorouracil has also caused onycholysis (47), showing the extreme sensitivity to this drug of the tissue anchoring the nail plate.

Several other groups of organic chemicals have caused nail loosening. Problems of this nature have been associated with the use of the agricultural products paraquat, diquat and dinitro-o-cresol $(5,49,50,51)$. Of 296 sugar cane spray operators examined, 55\% had clinical symptoms of paraquat exposure ranging from localized discoloration of the nails to nail loss (5). It was suggested that the nail damage caused by these chemicals was due to penetration into the nails' proliferative matrix via the posterior nailfold, with interruption of the normal process of keratinization $(41,50)$.

Detergents have also been implicated in the development of nail abnormalities $(4,52)$. An outbreak of contact dermatitis was associated with the introduction of enzyme detergents. Nail involvement here was, however, apparently rare (4). Several isolated incidents of occupational nail dystrophies have been reported. Coskey (53) has described the case of a female lifeguard who suffered onycholysis as a consequence of adding chlorine in the form of a $16 \%$ sodium hypochlorite solution to a public pool, Occupational koilonychia due to immersion in motor oil has been noted in mechanics (54), and recently Baran (55) has reported that rust-removing agents can cause acute onycholysis. An interesting new technique for the non-surgical avulsion of dystrophic nails developed by Farber and South $(56,57)$ has indicated that, at least for diseased nails, urea can diffuse freely across the nail plate. This technique has been used with some degree of success in the topical treatment of onychomy. cosis $(91,92)$. Non-diseased nails have also been avulsed non-surgically by the addition of $10 \%$ salicylic acid to the urea formulation (58). The action of urea is probably due to its ability to denature protein, facilitating keratolytic processes.

Abnormal nail pigmentation may be indicative of adsorption and penetration of the nail plate by a colouring material. Pigmentation may be due to several causes including systemic disorders, dermatological conditions, systemic drugs and local factors. In this review only local factors will be considered. The reader interested in other aspects of nail pigmentation abnormalities is referred to the review of Daniel and Osment (59). 
Discoloration of the nails due to contact with mercury was reported as early as 1907 (60). The discoloration is diffusely dispersed throughout the entire thickness of the nail and is due to mercuric sulphide formation $(6,61)$. Dye pigments in nail enamels are also thought to be capable of penetrating the nail plate $(62,63)$. Resorcinol monoacetate sometimes produces a yellowish-orange discoloration of the nail when in contact with lacquered nails (2). Other chemicals which are believed to penetrate the nail plate and cause discoloration include chromium salts (64) photographic developer (p-methyl-aminophenol sulphate hydroquinone) (65), and fluorescein (66).

\section{Therapeutic evidence of nail permeation}

Not all of the indirect evidence for nail permeation has concerned toxic reactions to applied chemicals. Clinical evidence in support of nail permeation is associated with the successful topical control of onychomycoses and psoriasis of the nails. Baranov et al. (67) claim to have successfully cured $87 \%$ of the 2400 -plus cases of fungal infections of the finger and toe nails they encountered using a complex medical strategy involving keratolytic (salicylic acid) and antifungal plasters. The infected nails were sluffed and non-infected nails grew back in their place. Botter (68) has reported that the nail condition of all twenty-seven onychomycotic patients he treated with topical miconazole exhibited substantial improvement. There was one relapse which was refractory to further treatment. Loosening of the infected nails occurred on average after 2 weeks with regrowth of new, uninfected nails. The nail took an average of 13 weeks to completely regenerate. It should be noted that concurrent systemic griseofulvin therapy was part of the therapeutic regimen. Follow-up studies on the use of topical miconazole for onychomycoses, using either a $2 \%$ cream (69) or a $2 \%$ alcoholic solution $(70,71)$, have met with comparable degrees of success. Glutaraldehyde has also been tried as an antimycotic for nails, with some encouraging clinical success. Suringa (72) applied a $10 \%$ aqueous solution of glutaraldehyde containing $0.1 \%$ polysorbate 80 (Tween 80 ) to a total of twenty-one nails. After 4 to 6 weeks surface infections were cleared. Deep infections required up to 4 months of topical therapy. Similar results were obtained by Grant (73) who also used mechanical debridement prior to treatment. Scopulariopsis onychomycosis has been successfully treated by the topical application of $1 \%$ natamycin in $60 \%$ dimethylsulphoxide (74). Of seven patients treated for 3 to 5 months only one did not respond favourably to therapy. It is interesting that these investigations used dimethylsulphoxide as a vehicle for the antimycotic. Dimethylsulphoxide is a potent enhancer of skin penetration $(75,76)$ and it may be worthwhile speculating as to its effects on nail permeation. Unfortunately, these authors (74) did not report on the effects of either the drug or the vehicle alone. Lastly, despite its previously mentioned drawbacks, topically applied fluorouracil ( $1 \%$ fluorouracil in propylene glycol/water, Fluoroplex ${ }^{\circledR}$, Herbert Laboratories, Irvine, Calif.) without occlusion has been shown to be beneficial in the treatment of psoriatic nails (48). A list of the chemicals which may permeate the nail plate on the basis of the above indirect evidence is presented in Table III.

\section{Direct evidence of nail permeation}

Several investigators have studied the water permeability of nail plate $(9,27,77,78,79)$. Burch and Winsor (77) mounted human nail, callus and stratum corneum in a simple permeation apparatus and observed that the diffusion of water through skin is slower than through the nail plate. Evaporative loss through nail was found to be similar to that observed for callus. In these investigations weight loss of a brass cup, filled with saline and covered at the open end by either a section of skin or nail plate was taken as a measure of permeability 
Table III. Chemicals indirectly associated with nail permeation

\begin{tabular}{lcl}
\hline \multicolumn{1}{c}{ Compound } & $\begin{array}{c}\text { Molecular } \\
\text { Weight }\end{array}$ & Reference \\
\hline Phenol & 94.1 & 33,34 \\
Formaldehyde & 30.0 & $3,33,36,37,38,39$ \\
Methyl methacrylate & 100.1 & 40 \\
Fluorouracil & 130.1 & $44,45,46,48$ \\
Paraquat & 186.2 (ion) & 5,57 \\
Diquat & 184.3 (ion) & 49,51 \\
Dinitro-o-cresol & 198.1 & 50 \\
Urea & 60.1 & 56,57 \\
Salicylic acid & 138.1 & 58,67 \\
Mercuric chloride & 271.5 & 6,61 \\
Resorcinol & 110.1 & 2 \\
p-methylaminophenolsulphate & 344.4 & 65 \\
Miconazole & 416.1 & $68,69,70,71,88$ \\
Glutaraldehyde & 100.1 & 72,73 \\
Natamycin & 665.75 & 74 \\
Sodium hypochlorite & 74.4 & 53 \\
\hline
\end{tabular}

through the nail and amounted to a water flux of $1.16-5.30 \mathrm{mg} \mathrm{cm}^{-2} \mathrm{~h}^{-1}$. Using a similar procedure, Baden et al. (27) reported that the flux of water across stratum corneum obtained from the abdomen is in the range 0.14 to $0.35 \mathrm{mg} \mathrm{cm}^{-2} \mathrm{~h}^{-1}$ but the nail ranges between 2.0 and $3.0 \mathrm{mg} \mathrm{cm}^{-2} \mathrm{~h}^{-1}$, showing it to be up to ten times more permeable. Soaking in 3:1 chloroform:methanol solution increased the stratum corneum's permeability to 1.9-3.2 $\mathrm{mg} \mathrm{cm}^{-2} \mathrm{~h}^{-1}$, essentially that observed with nail. The same procedure reportedly produced no effect on nail plate permeability. The greater permeability of nail relative to stratum corneum has been confirmed in vivo. Jacobi (78) and later Spruit (9) have designed water-sensing devices which can be placed over the body surface to measure insensible perspiration (Fig. 2). Spruit found the nail water vapour loss in vivo to average $2.40 \mathrm{mg} \mathrm{cm}^{-2}$

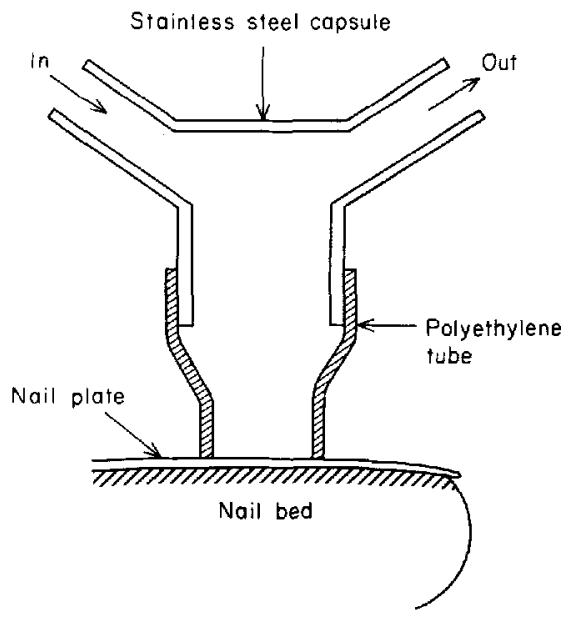

Figure 2. Device for measuring water loss across the nail (Spruit, 9). 


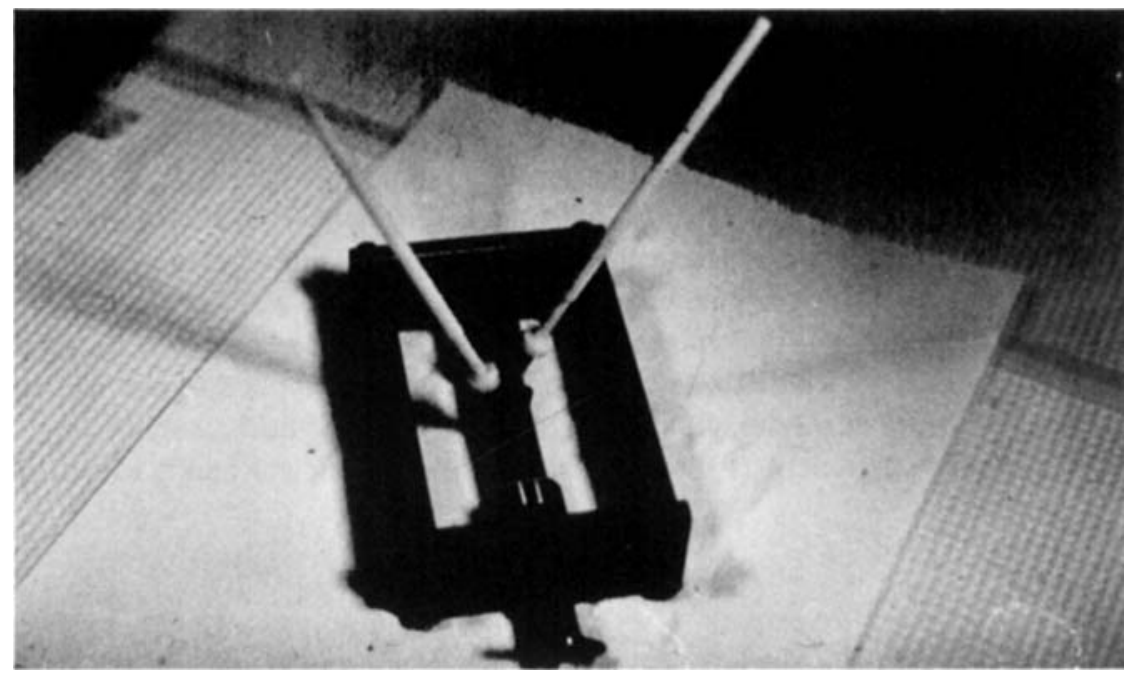

Figure 3. Diffusion cell, clamping device and stirring rods for measuring permeation across nail in vitro.

$\mathrm{h}^{-1}$, in very close agreement with the in vitro results of Burch and Winsor and Baden et al. Moreover, Spruit found that when the thickness of the nail was accounted for, there was very little variability in the permeation rate. Walters et al. (79) used a unique diffusion cell in which the nail plate was totally immersed (Figs 3 and 4) and they obtained a water flux of $12.6 \mathrm{mg} \mathrm{cm} \mathrm{ch}^{-2}$. This is about fivefold greater than found by the others who were mentioned, and consideration was given to the possibility that hydration of the dorsal surface may. increase the rate of water diffusion across this layer of the nail. As stated previously, the upper limit of the nail plate's capacity for water appears to be about $25 \%$ (27) and this is only two to three times greater than the normal water content of the nail. Therefore the greater flux of water reported by Walters et al. (79) seems a reasonable consequence of full hydration. Collectively analysed these studies indicate that nail plate is intrinsically up to one thousand times more permeable to water than is stratum corneum, given that the ratio of thickness of these tissues is about 100 (nail to stratum corneum). Delipidation of the stratum corneum reduces the permeability ratio to about 100 . This is

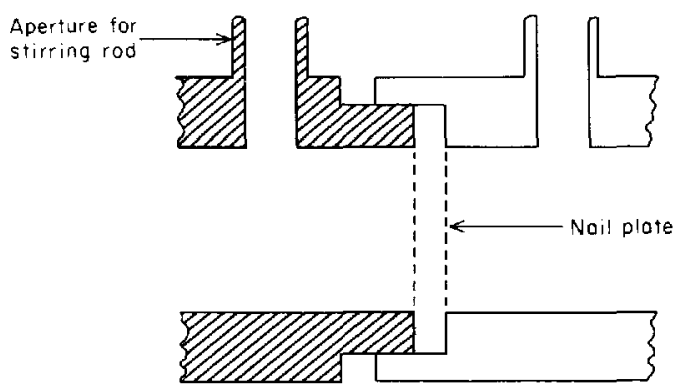

Figure 4. Cross-section of the interlocking flanges of the diffusion cell. 
evidence of a very different cellular and compositional organization between these two tissues.

Apart from the qualitative observation of Mitchell (34) that phenol diffuses through the nail plate, the only direct evidence of the permeation of organic chemicals through human nail plate in vitro appears to be that reported recently by Walters et al. (80). These investigators assessed the permeation of the smaller, liquid homologous $n$-alkanols. The $n$-alkanols have been used extensively in membrane characterization studies $(81,82,83,84)$ as they are a non-electrolyte series of systematically changing lipophilicity whose relative rates of transport are related to the specific nature of the membrane in question. Thus relative rates of transport to an extent yield insight into a membrane's physicochemical character. Fig. 5 gives a pair of plots of the logarithm of the permeability coefficient versus the alkyl chain length of the alcohol; one profile is for the situation where alcohols were applied to the nail in highly dilute aqueous solutions while the other is data obtained when the neat alcohols were applied.

The permeability coefficient $(P)$ is the mass transfer coefficient and is calculated from

$$
P=\frac{V\left(\frac{d c}{d t}\right)}{A \Delta C}
$$

where $\mathrm{V}$ is the volume of bathing medium in each half of the diffusion cell, $\frac{\mathrm{dc}}{\mathrm{dt}}$ is the slope of the pseudo-steady state portion of the penetration plots, $\mathbf{A}$ is the diffusional area and $\Delta \mathrm{C}$ is the concentration differential of the permeant across the membrane.

From aqueous solution, permeability coefficients decreased from $5.8 \pm 3.1 \times 10^{-3} \mathrm{~cm}$ $\mathrm{h}^{-1}$ for ethanol to $0.35 \pm 0.07 \times 10^{-3} \mathrm{~cm} \mathrm{~h}^{-1}$ for pentanol. The more hydrophobic alcohols, pentanol through octanol, have similar permeability rates whereas decanol's and dodecanol's

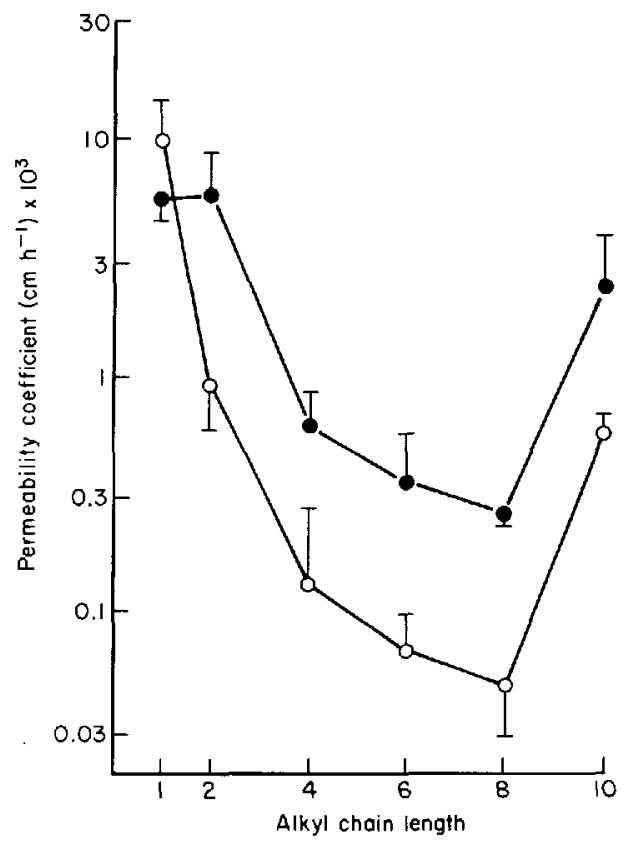

Figure 5. Permeability coefficients of the n-alkanols through nail plate from dilute aqueous solutions ( $\bullet$ ) and from neat alcohols (o) as a function of alkyl chain length (from ref. 85). 
permeabilities are successively increased by several multiples with respect to octanol's permeability. The profile for permeation from pure alcohols is similar (85). In the latter case, however, the permeability coefficients fall systematically from $9.73 \pm 5.06 \times 10^{-3} \mathrm{~cm} \mathrm{~h}^{-1}$ for methanol to $0.05 \pm 0.02 \times 10^{-3} \mathrm{~cm} \mathrm{~h}^{-1}$ for octanol. As with dilute solutions, the permeability rate of decanol (from decanol) is increased tenfold over that of octanol (from octanol). The overall parallelism in the permeability profiles under these separate circumstances of application is an indication that external concentration of the alcohols is the important determinant of their permeation velocities through the nail plate matrix. The separation of the profiles suggests a facilitating role of water. Data for all the alcohols studied is presented in Table IV. These data suggest that, as a membrane, the hydrated nail behaves as if it were a hydrogel of highly ionic character as there are systematic decreases in the mass transfer coefficients as the alkyl chain is lengthened. The substantial increases in permeation for decanol and dodecanol indicate that permeability has become sensitive to oil/water partitioning and,

Table IV. Nail plate permeability coefficients for $n$-alkanols from dilute aqueous solutions and neat alcohols

\begin{tabular}{lcc}
\hline & Permeability coefficient $\left(\mathrm{cm} \mathrm{h}^{-1} \times 10^{3}\right)^{*}$ \\
Permeant & $\begin{array}{c}\text { From dilute } \\
\text { aqueous solutions }\end{array}$ & $\begin{array}{c}\text { From neat } \\
\text { alcohols }\end{array}$ \\
\hline Methanol & $5.6 \pm 1.2$ & $9.73 \pm 5.06$ \\
Ethanol & $5.8 \pm 3.1$ & $0.91 \pm 0.34$ \\
Propanol & $0.83 \pm 0.15$ & - \\
Butanol & $0.61 \pm 0.27$ & $0.13 \pm 0.15$ \\
Pentanol & $0.35 \pm 0.07$ & - \\
Hexanol & $0.36 \pm 0.23$ & $0.07 \pm 0.03$ \\
Heptanol & $0.42 \pm 0.12$ & - \\
Octanol & $0.27 \pm 0.03$ & $0.05 \pm 0.02$ \\
Decanol & $2.5 \pm 1.7$ & $0.59 \pm 0.13$ \\
Dodecanol & $4.1 \pm 2.7$ & -- \\
\hline
\end{tabular}

*Data include standard deviation.

in this regard, are consistent with the observations of Baden (19), who equilibrated radiolabelled fatty acids and their sodium salts in aqueous solution with pieces of human nail plate, finding that the partition coefficients increased exponentially from alkyl chain length of $\mathrm{C}_{7}$ to $\mathrm{C}_{16}$. The permeation behaviour for the two higher alcohols is consistent with the onset of significance of a parallel pathway of lipophilic character possibly represented by lipids of the cell membranes and intercellular space. However, the possibility of interaction between $C_{10}$ and $C_{12}$ alkyl chains and keratin cannot be excluded as the means whereby these chemicals migrate through the nail material. Unique interactions between surfactants having $C_{10}$ and $C_{12}$ alkyl chains and skin have been shown to occur (86) and, according to Breuer (87), such long chain alcohols can bind to keratinous tissues.

The most striking feature of these data is the total departure from behaviour seen with the same permeants in other body membranes such as human and animal skin and animal vaginal and gastro-intestinal mucoses. The permeability patterns for these latter membranes show the membranes function to a great extent as lipid barriers; the nail plate, on the other hand, appears to exclude compounds as they become more hydrophobic, an exactly opposite behaviour. 
Schaefer and Stuttgen (88) have taken a different but complimentary approach to illustrating that the nail plate is permeable by extending their ingeneous stratum corneum sectioning technique to the study of the nail plate. They carefully dermatomed the nail plate which had been exposed to radiolabelled miconazole (89), oxiconazole or econazole (93) into thin shavings and analysed the concentration of drug in each slice, developing in this manner a picture of the concentration gradient in the nail. The concentration across the nail dropped about 1000-fold from the outer surface to the inner surface. Concentrations in the deepest shavings appeared to increase suggesting a change in the physicochemical nature of the deeper layers, perhaps entry into the subnail tissue. It is also interesting that a change in gradient occurs at about $100 \mu \mathrm{m}$ depth in the nail with the shallower gradient in the external dorsal plate. This is consistent with the known difference in hardness of the respective strata. This interpretation must be treated as speculative given the degree of scatter of the data. It is also important to point out that concentration gradient profiles to some extent give a false picture of diffusional processes as only the mobile, unbound molecules in a given plane determine the effective gradient, and binding (adsorption) in the various planes in the nail plate, if it occurs, cannot be factored used the technique of Schaefer and Stuttgen.

On the basis of all the evidence to date the possibility exists that two distinct pathways for penetration across the nail are operative. One pathway is hydrophilic and explains the relatively rapid diffusion of water and highly water-soluble compounds such as urea, glutaraldehyde, methanol and ethanol and possibly paraquat and diquat. The second presumed pathway appears to be a more minor route of lipophilic character which is significant only in the extremes of non-polarity. It allows the diffusion of such lipid-soluble compounds as decanol and dodecanol. For the most part it is not yet possible to assign other known permeants to one or the other of these alternative mechanisms. However, it appears that polarity favours permeability, a behaviour without previous precedent.

\section{IMPLICATIONS OF NAIL PENETRATION}

The collective physicochemical and clinical observations point to one general conclusion, namely that the nail is breachable by a variety of chemical substances ranging from small polar and non-polar non-electrolytes and salts to large complex drug molecules. If there is a cut-off point for mass transfer in terms of molecular weight it has not yet been located. Molecules as large as natamycin (mol. wt $=666$ ) apparently pass through the structure. It seems likely, therefore, that many of the chemicals which come into contact with the nail plate either deliberately, as for cosmetic or medical reasons, or by accident may in fact diffuse through the plate, and the threat always exists of adverse effects in sensitive individuals. The cosmetic formulator should therefore not be deluded into thinking of the nail as a chemically impervious structure when considering the development of a new formulation or the addition of new excipients to an existing formulation. In this regard it would not be an arduous task, using the techniques outlined above, to perform permeation experiments on possible formulation additives in order to select those with the least propensity to elicit adverse reactions.

\section{POSSIBLE FUTURE DIRECTIONS}

Preliminary experiments have been performed to determine the effects of organic solvents, such as dimethylsulphoxide (DMSO) and isopropanol on nail permeation (85). DMSO was 
found to retard the permeation of methanol and hexanol across the nail plate. Isopropyl alcohol reduces the permeation rate of hexanol but had little influence on that of methanol. These studies are viewed as being important to the successful formulation of drugs used in the treatment of nail infections, but the data obtained so far suggest that solvents with proven efficacy as skin 'penetration enhancers' show little promise as enhancers of nail plate permeability $(85,90)$.

Given the unusual behaviour of the nail, the influence of $\mathrm{pH}$ on the permeation of weak electrolytes is also an open question. Preliminary investigations with an organic weak electrolyte suggests that unusual $\mathrm{pH}$-permeability characteristics are demonstrated, with the ionic form nearly as permeable as the free species (94). A full study of the influence of molecular size on diffusion coefficients is necessary.

It does not seem unreasonable to predict that it may soon be possible for the pharmaceutical manufacturer to chemically tailor drugs which will prove more effective in the topical management of nail infections. Further it also appears that cosmetic scientists will soon be able to more prudently select the raw materials for nail products to minimize the troubling consequences of perungual absorption.

\section{REFERENCES}

1. Sulzberger, M. B. Hypersensitivity to nail polish. Arch. Derm. Syph. 36 460-461 (1937).

2. Loveman, A. B. and Fliegelman, M. T. Discolouration of the nails. Arch. Derm. 72 153-156 (1955).

3. Rein, C. R. and Rogin, J, R. Allergic eczematous reactions of the nail bed to 'under coats'. Arch. Derm. 61 971-983 (1950).

4. Hodgson, G. and Mayon-White, R. T. Acute onychia and onycholysis due to an enzyme detergent. Br. Med. J. 3352 (1971).

5. Hearn, C. E. D. and Keir, W. Nail damage in spray operators exposed to paraquat. Br. J. industr. Med. 28 399-403 (1971).

6. Butterworth, T. and Strean, L. P. Mercurial pigmentation of nails. Arch. Derm. 88 55-57 (1963).

7. Kanwar, A. J. and Singh, O. P. Onycholysis secondary to tetracycline hydrochloride. Cutis 23 657658 (1979).

8. Frank, S. B., Cohen, H. J. and Minkin, W. Photo-onycholysis due to tetracycline hydrochloride and doxycycline. Arch. Derm. 103 520-521 (1971).

9. Spruit, D. Measurement of water vapor loss through human nail in vivo. J. Invest. Dermatol. $56359-$ 361 (1971).

10. Forslind, B. and Thyresson, N. On the structure of the normal nail. Arch. Derm. Forsch. 254 199204 (1975).

11. Hashimoto, K. Ultrastructure of the human toenail I: Proximal nail matrix. J. Invest. Dermatol. 56 235-246 (1971).

12. Bean, W. B. Nail growth. Thirty-five years of observation. Archs. intern. Med. 140 73-76. (1980).

13. Kandil, E. Accurate measurement of nail growth. Int. J. Dermatol. 11 54-56 (1972).

14. Robson, J. R. K. Hardness of finger nails in well-nourished and malnourished populations. $B r . J$. Nutr. 32 389-394 (1974).

15. Zaias, N. The movement of nail bed. J. Invest. Dermatol. $48402-403$ (1967).

16. Hashimoto, H., Bernard, G. G., Nelson, R. and Lever, W. F. The ultrastructure of the skin of human embryos III: The formation of the nail in 16-18 week old embryos. J. Invest. Dermatol. 47 205-217 (1966).

17. Hashimoto, K. Ultrastructure of human toe nail II: Keratinization and formation of the marginal band. Ultrastruct. Res. $36391-410$ (1971).

18. Caputo, R. and Dadati, E. Preliminary observations about the ultrastructure of the human nail plate treated with thioglycolic acid. Arch. klin. exp. Derm. 231 344-354 (1968).

19. Baden, H. P. The physical properties of nail. J. Invest Dermatol. 55 115-122 (1970).

20. Forslind, B. Biophysical studies of the normal nail. Acta Derm.-venereol. 50 161-168 (1970). 
21. Zaias, N. and Alvarez, J. The formation of the primate nail plate, an autoradiographic study in squirrel monkey. J. Invest. Dermatol. 51 120-136 (1968).

22. Hashimoto, K. Ultrastructure of the human toenail: Cell migration, keratinization and formation of the intercellular cement. Arch. Derm. Forsch. 240 1-22 (1971).

23. Spearman, R. I. C. The physiology of the nail. Physiol. Pathophysiol. Skin. 5 1811-1855 (1978).

24. Silver, H. and Chiego, B. Nails and nail changes II; Modern concepts of anatomy and biochemistry of the nails. J. Invest. Dermatol. 3 133-142 (1940).

25. Vellar, O. D. Composition of human nail substance. Am. J. Clin. Nutr. 23 1272-1274 (1970).

26. Sobolewski, S., Lawrence, A. C. K. and Bagshaw, P. Human nails and body iron. J. clin. Path. 31 1068-1072 (1978).

27. Baden, H. P., Goldsmith, L. A. and Fleming, B. A comparative study of the physicochemical properties of human ketatinized tissues. Biochim. biophys. Acta 322 269-278 (1973).

28. Ogura, R., Know, J. M., Griffin, A. C. and Kusuhara, M. The concentration of sulfhydril and disulfide in human epidermis, hair and nail. J. Invest. Dermatol. 38 69-75 (1962).

29. Gillespie, J. M. and Marshall, R. C. Proteins of human hair and nail. Cosmet. Toil. 95 29-34 (1980).

30. Bulgin, J. J. and Vinson, L. J. The use of differential thermal analysis to study bound water in stratum corneum membranes. Biochim. biophys. Asta 136 551-560 (1967).

31. Reinertson, R. P. and Wheatley, V. R. Studies on the chemical composition of human epidermal lipids. J. Invest. Dermatol. 32 49-59 (1959).

32. Scheuplein, R. J. and Morgan, L. J. Bound water in keratin membranes measured by a microbalance technique. Nature 214456 (1967).

33. Sulzberger, M. N., Rein, C. R., Fanburg, S. J., Wolf, M., Shair, H. M. and Popkin, G. L. Allergic eczematous reactions of the nail bed. Persistant subungual and ungual changes based on contact with undercoats containing artificial resins and rubbers. J. Invest. Dermatol. 267-72 (1948).

34. Mitchell, J. H. Nail changes following the use of 'base coats'. Med. Clins N Am. 33 95-107 (1949).

35. Reisch, M. Nail changes due to new base coat. Archs Derm. $80230-231$ (1957).

36. March, C. H. Allergic contact dermatitis to a new formula to strengthen.nails. Archs Derm. 93720 (1966).

37. Lazar, P. Reactions to nail hardeners. Archs Derm. $96446-448$ (1966).

38. Van de Erve, J. Fingernail necrosis from nail hardener formula. J. So. Carol. Med. Ass. 6318 (1967).

39. Donsky, H. J. Onycholysis due to nail hardeners. Can. med. Ass. J. 96 1375-1376 (1967).

40. Fisher, A. A., Franks, A. and Glick, H. Allergic sensitization of the skin and nails to acrylic plastic nails. I. Allergy 28 84-88 (1957).

41. Samman, P. D. The Nails in Disease 2nd edn. 128 (1972) (C. C. Thomas, Springfield).

42. Bentley-Phillips, B. Dystrophies due to nail cosmetics. So. Afr. med. J. 44 1293-1295 (1970).

43. Schlossman, M. L. Modern nail enamel technology. J. Soc. Cosmet. Chem. 31 29-36 (1980).

44. Tanenbaum, M. H. Onychodystrophy after topically applied fluorouracil for warts. Archs Derm. $103225-226$ (1971).

45. Goldman, L., Blaney, D. J. and Cohen, W. Onychodystrophy after topical 5-fluorouracil. Archs Derm. 88 97-98 (1963).

46. Shelley, W. B. Onycholysis due to topical 5-fluotouracil. Acta Derm.-venereol. 52 320-322 (1972).

47. Katz, M. E. and Hansen, T. W. Nail plate-nail bed separation. An unusual side effect of systemic fluorouracil administration. Archs Derm. 115 860-861 (1979).

48. Fredriksson, T. Topically applied fluorouracil in the treatment of psoriatic nails. Archs Derm. 110 735-736 (1974).

49. Clark, D. G. and Hurst, E. W. The toxicity of diquat. Br. J. ind. Med. 27 51-55 (1970).

50. Baran, R. L. Nail damage caused by weed killers and insecticides. Archs Derm. 110467 (1974).

51. Samman, P. D. and Johnston, E. N. M. Nail damage associated with handling of parquat and diquat. Bri. med. J. 1 818-819. (1969).

52. Cornbleet, T. and Bettenhausen, J. Onychiae and paronychiae: Detergents and monilia. Archs Derm. 88230 (1963).

53. Coskey, R. J. Onycholysis from sodium hypochlorite. Archs Derm. 10996 (1974).

54. Dawber, R. Occupational koilony chia. Clin. exp. Dermatol. $2115-116$ (1977).

55. Baran, R. Acute ony cholysis from rust-removing agents. Archs Derm. 116 382-383 (1980).

56. Farber, E. M. and South, D. A. Urea ointment in the nonsurgical avulsion of nail dystrophies. Cutis 22 689-692 (1978).

57. South, D. A. and Farber, E. M. Urea ointment in the nonsurgical avulsion of nail dystophies - a reappraisal. Cutis 25 609-612 (1980). 
58. Buselmeier, T. J. Combination urea and salicylic acid ointment nail avulsion in nondystrophic nails: A follow-up observation. Cutis 25 397-405 (1980).

59. Daniel, C. R. and Osment, L. S. Nail pigmentation abnormalities: their importance and proper examination. Cutis 25 595-607 (1980).

60. Vorners, von Onychia pigmentosa. Munchen med. Wchnschr. 54671 (Cited in ref. 62) (1907).

61. Callaway, J. L. Transient discoloration of the nails due to mercuric bichloride. Arch. Derm. Syph. 36 62-64 (1937).

62. Shellow, H. Discoloration of the nails due to nail enamel. Arch. Derm. Syph. 42 480-481 (1940).

63. Calnan, C. D. Reactions to artificial colouring materials. J. Soc. Cosmet. Chem. 18 215-223 (1967).

64. Baran, R. Pigmentations of the nails (chromonychia). J. Derm. Surg. Oncol. 4 250-253 (1978).

65. Zaias, N. and Baden, H. P. Disorders of nails. In (T. B. Fitzpatrick, K. A. Arndt, W. H. Clark, A. Z. Eisen, E. J. Van Scott and J. H. Vaughan, eds) Dermatology in General Medicine 331-353 (1971) (McGraw-Hill, New York).

66. Hendricks, A. A. Yellow lunulae with fluorescence after tetracycline therapy. Archs Derm. 116 438-439 (1980).

67. Baranov, A. F., Marochkina, I. A., Konopikhina, G. A., Kolokolova, N. V., Jakimenko, D. V. and Panova, P. M. Fxperiences in treatment of onychomycoses with keratoly tics and fungicidal plasters. Vest. Derm. Vener. 36 65-67 (1962).

68. Botter, A. A. Topical treatment of nail and skin infections with miconazole, a new broad-spectrum antimycotic. Mykosen 14 187-191 (1971).

69. Heinke, E. Clinical experience with miconazole with special consideration of the conservative treatment of ony chomycosis and paronychia. Mykosen 15 405-407 (1972).

70. Vanderdonckt, J., Lauwers, $W$. and Bockaert, J. Miconazole alcoholic solution in the treatment of mycotic nail infections. Mykosen $19251-256$ (1976).

71. Achten, G., Degreef, H. and Dockx, P. Treatment of onychomycosis with solution of miconazole $2 \%$ in alcohol. Mykosen 20 251-256 (1977).

72. Suringa, D. W. R. Treatment of superficial onychomycosis with topically applied glutaraldehyde. Archs Derm. 102 163-167 (1970).

73. Grant, L. V. A further look at the treatment of onychomycosis with topical glutaraldehyde.J. Am. Pod. Assoc. 64 158-160 (1974).

74. Onsberg, P. and Stahl, D. Scopulariopsis onychomycosis treated with natamycin. Dermatologica 160 57-61 (1980).

75. Baker, H. Experimental studies on the influence of vehicles on percutaneous absorption. $J$. Soc. Cosmet. Chem. 20 239-252 (1969).

76. Chandrasekaran, S. K., Campbell, P. S. and Michacls, A. S. Effect of dimethyl sulphoxide on drug permeation through human skin. AIChE J. 23 810-816 (1977).

77. Burch, G. E. and Winsor, T. Diffusion of water through dead planter, palmer and torsal human skin and through toenails. Arch. Derm Syph. 53 39-41 (1946).

78. Jacobi, $O$. Die nagel des lebenden menschen und die perspiratio insensibilis. Arch. klin. exp. Derm. 214 559-572 (1962).

79. Walters, K. A., Flynn, G. L. and Marvel, J. R. Physicochemical characterization of the human nail 1: Pressure sealed apparatus for measuring nail plate permeabilities. J. Invest. Dermatol. 76 76-79 (1981).

80. Walters, K. A., Flynn, G. L. and Marvel, J. R. Physicochemical characterization of the human nail. Permeation pattern for water and the homologous alcohols and differences with respect to the stratum corneum. J. Pharm. Pharmac. 35 28-33 (1983).

81. Ho, N. F. H., Park, J. Y., Morozowich, W. and Higuchi, W. I. Physical model approach to the design of drugs with improved intestinal absorption. In (E. B. Roche, ed.) Design of Biopharmaceutical Properties Through Prodrugs and Analogues 136-227 (1977) (American Pharmaceutical Association, Academy of Pharmaceutical Sciences).

82. Behl, C. R., Flynn, G. L., Kurihara, T., Harper, N., Smith, W. M., Higuchi, W. I., Ho, N. F. H. and Pierson, C. L. Hydration and percutaneous absorption I: Influence of hydration on water and alkanol absorption through hairless mouse skin. J. Invest. Dermatol. 75 346-352 (1980).

83. Hwang, H., Owada, E., Yotsunganagi, T., Suhardja, L., Ho, N. F. H., Flynn, G. L. and Higuchi, W. I. Systems approach to vaginal delivery of drugs II: In situ vaginal absorption of unbranched aliphatic alcohols. J. Pharm. Sci. 65 1574-1578 (1976).

84. Flynn, G. L. and Smith, R. W. Membrane diffusion III: Influence of solvent composition and permeant solubility on membrane transport. J. Pharm. Sci. 61 61-66 (1972). 
85. Walters, K. A. and Flynn, G. L. Solvent influences on the transport of homologous chemicals across human nail plate. J. Pharm. Pharmac. 33 6P (1981).

86. Prottey, C. The molecular basis of skin irritation. In (M. M. Breuer, ed.) Cosmetic Science $1275-349$ (1978) (Academic Press, London).

87. Breuer, M. M. The interaction between surfactants and keratinous tissues. J. Soc. Cosmet Chem. 30 41-64 (1979).

88. Schaefer, H. and Stuttgen, G. (Unpublished report) Biopharmaceutical problems in the treatment of superficial mycoses.

89. Schaefer, H. and Stuttgen, G. Absolute concentrations of an antimycotic agent, econazole, in the human skin after local application. Arzneimittel-Forsch. 26 432-435 (1976).

90. Kligman, A. M. Topical pharmacology and toxicology of dimethyl sulfoxide - Part 1.J. Am. med. Ass. 193 796-804 (1965).

91. White, M. I. and Clayton, Y. M. The treatment of fungus and yeast infections of nails by the method of chemical removal. Clin. Exp. Dermatol. 7 273-276 (1982).

92. Rollman, O. Treatment of onychomycosis by partial nail avulsion and topical miconazole. Dermatologica 165 54-61 (1982).

93. Stuttgen, G. and Bauer, E. Bioavailability, skin and nail penetration of topically applied antimycotics. Mykosen 25 74-80 (1982).

94. Walters, K. A., Flynn, G. L. and Marvel, J. R. Unpublished observations (1980). 